\title{
Maternal and perinatal morbidity and mortality in severe pre- eclampsia and eclampsia in a tertiary care hospital: a prospective study
}

\author{
Neeta Chaudhary, Natasha Tyagi*, Smita Tyagi, Shivani Singhal
}

Department of Obstetrics and Gynecology, Muzaffarnagar Medical College, Muzaffarnagar, Uttar Pradesh, India

Received: 25 January 2019

Accepted: 05 March 2019

* Correspondence:

Dr. Natasha Tyagi,

E-mail: nats.hookedbyrain@gmail.com

Copyright: (C) the author(s), publisher and licensee Medip Academy. This is an open-access article distributed under the terms of the Creative Commons Attribution Non-Commercial License, which permits unrestricted non-commercial use, distribution, and reproduction in any medium, provided the original work is properly cited.

\section{ABSTRACT}

Background: Hypertensive disorders of pregnancy are a leading cause of maternal and perinatal morbidity and mortality worldwide. In India, they account for the third most important cause of maternal mortality. The objective of this study was to evaluate maternal and perinatal outcome and complications in cases with severe pre-eclampsia and eclampsia and measures to prevent them.

Methods: A prospective study was carried out on 100 patients with severe pre-eclampsia and eclampsia in tertiary care referral hospital over a period of one year i.e. from November 2017 to October 2018. Only those cases with initial blood pressure reading of $\geq 160 / 110 \mathrm{mmHg}$ or presenting with eclampsia were in included in the study. Detailed history and examination was carried out. Investigations and management were carried out as per standardized department protocol and maternal and fetal outcomes were analyzed.

Results: $48 \%$ of women were between $21-25$ years age, $82 \%$ were from rural area, and $86 \%$ cases were unbooked, $68 \%$ cases were primigravida. Liver Function Tests were deranged in $18 \%$ of the patients and $19 \%$ had abnormal Renal Function Tests. Labetalol was the most commonly used antihypertensive. Lower segment cesarean section was the mode of delivery in $59 \%$ of the cases. Most common maternal complication was Eclampsia. There were 5 maternal deaths i.e. maternal death rate was $5 \% .54 .3 \%$ of live births needed NICU admission and out of these $50 \%$ were preterm deliveries.

Conclusions: Accessible healthcare and health education and awareness regarding antenatal checkup for all women will lead to early detection of severe pre-eclampsia. Hence, early treatment and management of patient's complications will certainly improve the maternal and perinatal outcome.

Keywords: Eclampsia, Maternal morbidity, Maternal mortality, Perinatal morbidity, Pre-eclampsia, Perinatal mortality

\section{INTRODUCTION}

Hypertensive disorders complicate about 5-10\% of all pregnancies worldwide. Hypertension along with haemorrhage and infection form a deadly triad that contributes greatly to maternal morbidity and mortality rates. $^{1}$ The WHO systematically reviews maternal mortality worldwide and in developed countries, $16 \%$ of maternal deaths were reported to be due to hypertensive disorders. ${ }^{2}$ In India, hypertensive disorders account for the third most important cause of maternal mortality. ${ }^{3}$

Pre-eclampsia is a pregnancy-specific syndrome that can affect virtually every organ system. Severe pre-eclampsia has a BP reading of $\geq 160 / 110 \mathrm{mmHg}$ and $5 \mathrm{gm}$ protein in 24 hours urine specimen or symptoms of an organ damage like deranged LFT, thrombocytopenia, oligouria, visual disturbances, pulmonary oedema etc. Eclampsia is 
defined as generalized tonic clonic seizures and/or unexplained comatose in a woman with pre-eclampsia.

In spite of advances in medicine, pre-eclampsia and eclampsia continue to remain leading causes of maternal and perinatal mortality and morbidity throughout the world. Severe pre-eclampsia can lead to multiple lifethreatening complications like eclampsia, cerebral haemorrhage, cardiovascular complications, hepatic failure, acute renal failure, pulmonary oedema, ARDS (Acute Respiratory Distress Syndrome), DIC (Disseminated Intravascular Coagulation), HELLP Syndrome (Haemolysis, Elevated Liver Enzymes, Low Platelet), retinal detachment, cortical blindness, hypoxic cerebral damage and even maternal death.Fetal complications are mainly due to utero-placental insufficiency leading to FGR (Foetal Growth Retardation) and complications due to prematurity. Despite advances in medical practice, pre-eclampsia and eclampsia still remains a leading cause of maternal and perinatal morbidity and mortality throughout the world. Clinical studies of pre-eclampsia and eclampsia can be used for the evaluation of safe motherhood program at population level.

Maternal and perinatal morbidity and mortality due to pre-eclampsia can only be prevented by access to quality antenatal care, early diagnosis and recognition of risk factors, careful monitoring and timely interventions.

\section{METHODS}

The present study was undertaken in a tertiary care referral hospital with the aim of evaluating the maternal and perinatal outcome and complications of severe preeclampsia and eclampsia.

\section{Inclusion criteria}

- $\quad$ Patients of severe preeclampsia or eclampsia from 28 weeks onwards till term who were either followed up in the OPD and were admitted later on or came unbooked in emergency.

- $\quad$ BP reading of $\geq 160 / 110 \mathrm{mmHg}$ on two occasions 6 hours apart was the criteria followed for categorizing severe pre-eclampsia. Eclampsia was defined as presence of seizures in women with pre-eclampsia which could not be attributed to other causes.

\section{Exclusion criteria}

- $\quad$ Patients with chronic hypertension (before 20 weeks of gestation), chronic renal disease, connective tissue disorders and mild pre-eclampsia were not included in the study.

\section{Methodology}

The present study was carried out in department of obstetrics and gynaecology in collaboration with department of Pediatrics in Muzaffarnagar Medical College, Muzaffarnagar, Uttar Pradesh from November 2017 to October 2018. It was done on 100 pregnant women of severe pre-eclampsia and eclampsia who were either follow up patients and were admitted from OPD or who came unbooked in emergency.

On admission, detailed history regarding age, parity, period of gestation, sign and symptoms, obstetric and family history was recorded from the patient or patient's attendant, as appropriate. After that, general physical, abdominal and per-vaginal examinations were carried out. Investigations like complete hemogram, platelet count, liver function test, renal function test, coagulation profile, fundoscopy and 24 hours urine for protein were performed in all the patients.

Obstetric management was carried out as per existing protocol in the department. Blood pressure was controlled by Nifedipine and Labetalol-both orally or parenterally, singly or in combination as needed.

Magnesium Sulphate was the anti-convulsant of choice used both as prophylaxis and treatment according to the Pritchard's regimen. Injection Betamethasone, 2 doses of $12 \mathrm{mg}, 24$ hours apart was administered intramuscularly to accelerate fetal lung maturity if gestation age was less than 34 weeks.

Induction was done with Misoprostol or Cervigel depending upon the parity, scarred or unscarred uterus, bishops score and associated complicating factors. Timing of induction varied from patient to patient depending upon the blood pressure, foetal biophysical profile and maternal status assessed clinically and by her biochemical parameters.

Details of labour whether it was spontaneous or induced, method of induction and mode of delivery were recorded. Preterm delivery was defined as delivery before 37 weeks of gestation.

Neonatal morbidity was estimated by number of newborns needing NICU admission. Maternal and perinatal complications were noted down. At the end of the study, the data was compiled and analysed.

\section{RESULTS}

Out of 100 patients in the present study, $8 \%$ were <20yrs of age, $48 \%$ were $21-25$ years of age, $36 \%$ were $26-30$ yrs of age, 5\% were between 31-35 years and 3\% were $>35$ yrs. In present study maximum number of patients were between 21-25 years (Figure 1).

Out of 100 patients $68 \%$ cases were Nulliparous and $32 \%$ were multiparous. This shows that severe preeclampsia and eclampsia has greater incidence in nulliparous women (Figure 2). Out of 100 patients $8 \%$ were $<32$ weeks, $61 \%$ were $32-37$ weeks and $31 \%$ were $>37$ wks. It 
was observed that the majority i.e. maximum number of the patients $(61 \%)$ presented at gestational age between 32 wk1d to 37 weeks (Figure 3).

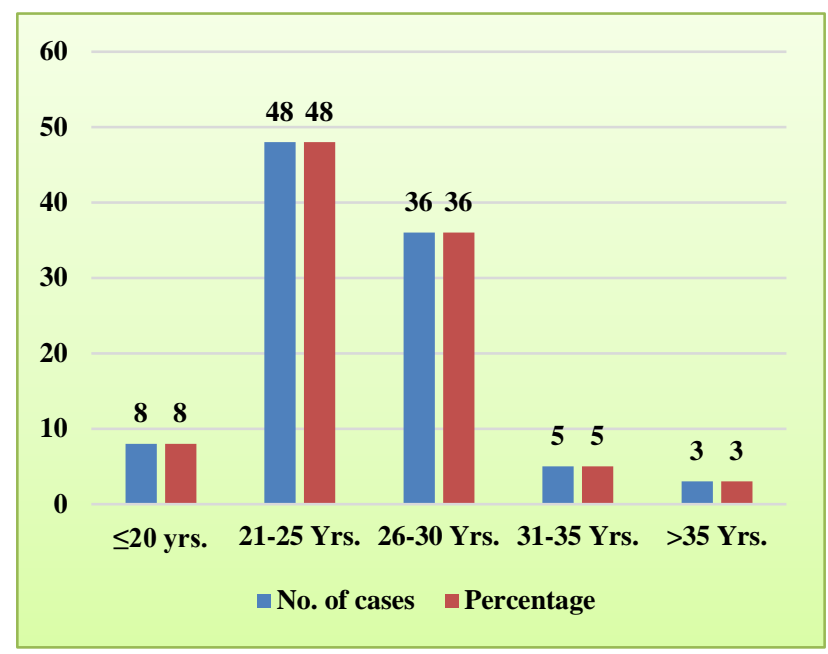

Figure 1: Age of the patients enrolled.

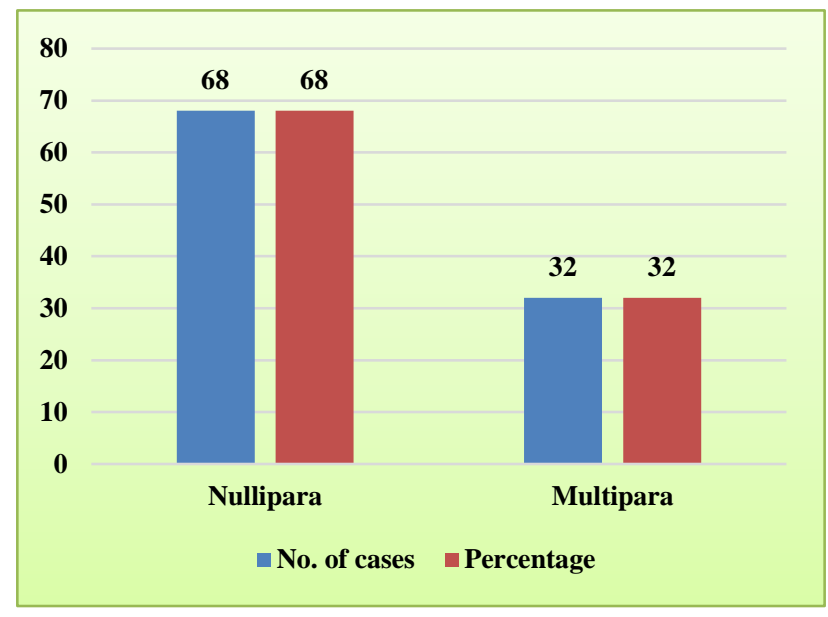

Figure 2: Parity of the patients.

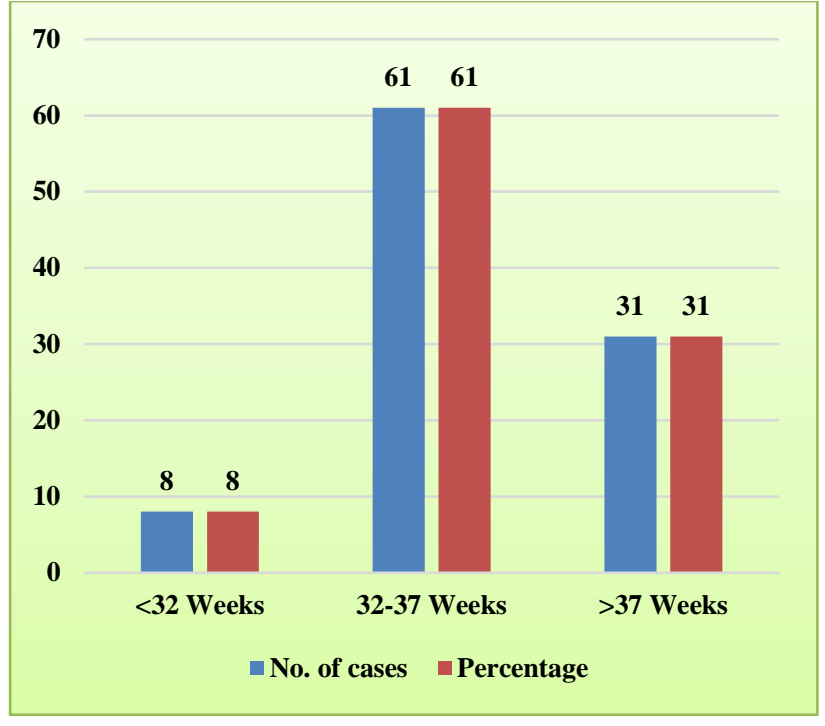

Figure 3: Gestational age of the patients.

Liver enzymes SGOT and SGPT were elevated in $18 \%$, S. bilirubin was elevated in $9 \%$ and $\mathrm{LDH}$ was elevated in $11 \%$. Renal function test, blood Urea was elevated in $13 \%$, S. creatinine and Uric acid was elevated in $19 \%$ patients. Platelet count was <one lakh in $25 \%$, PT/INR deranged in $14 \%$ and hemolysis on peripheral smear seen in $8 \%$ (Table 1). Out of $100,32 \%$ patients were put on only Labetalol and $68 \%$ were put on both labetalol and nifedipine.

Labetalol was the most commonly used drug in the present study either single or in combination (Figure 4). Out of 100 patients, $36 \%$ had normal vaginal delivery, $59 \%$ underwent LSCS, 3\% had instrumental delivery and $2 \%$ had hysterotomy (Figure 5). Out of 59 patients who underwent caesarean $8(13.6 \%)$ were of previous Csection, 21 (35.6\%) had foetal distress, 14(23.7\%) were of failed induction, $9(15.2 \%)$ had CPD and 7(11.9\%) had abruption.

Table 1: Abnormality in blood investigations.

\begin{tabular}{|c|c|c|c|c|}
\hline \multirow{2}{*}{ LFT } & SGOT & SGPT & LDH & Serum bilirubin \\
\hline & $>70$ IU/I & $>70$ IU/I & $>600$ & $>1.2 \mathrm{mg} / \mathrm{dl}$ \\
\hline No. of cases & 18 & 18 & 11 & 9 \\
\hline$\%$ of cases & $18 \%$ & $18 \%$ & $11 \%$ & $9 \%$ \\
\hline \multirow{2}{*}{ RFT } & Blood urea & Serum creatinine & Serum uric acid & \\
\hline & $>40$ & $>0.9$ & $>7$ & \\
\hline No. of cases & 13 & 19 & 19 & \\
\hline$\%$ of cases & $13 \%$ & $19 \%$ & $19 \%$ & \\
\hline \multirow{2}{*}{ Coagulation profile } & Platelet count & Deranged & \multirow{2}{*}{$\begin{array}{l}\text { Peripheral smear with } \\
\text { hemolysis }\end{array}$} & \\
\hline & $<1$ lakh & $\mathrm{Pt} / \mathrm{INR}$ & & \\
\hline No. of cases & 25 & 14 & 8 & \\
\hline$\%$ of cases & $25 \%$ & $14 \%$ & $8 \%$ & \\
\hline
\end{tabular}




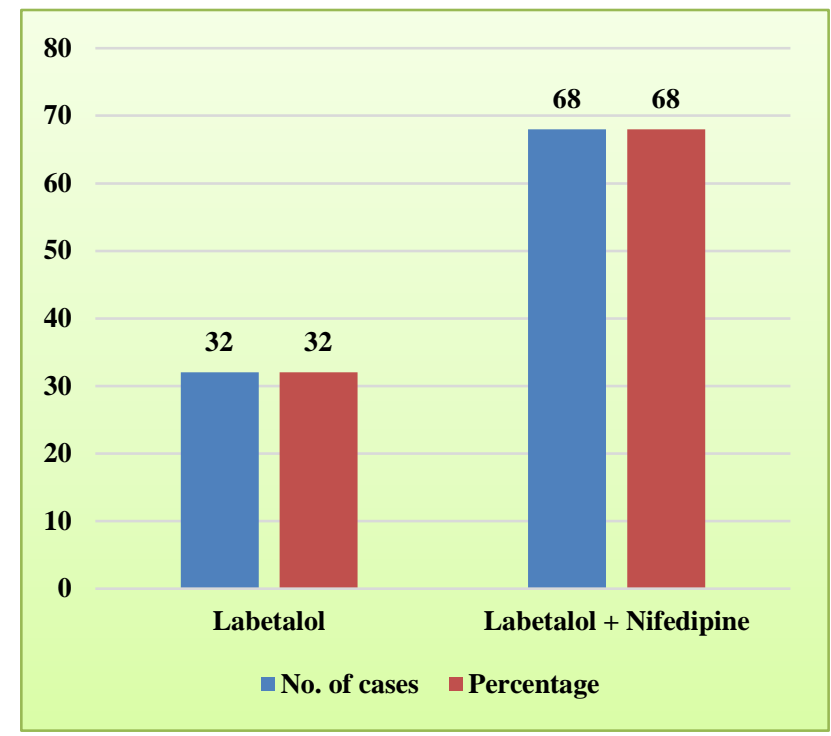

Figure 4: Antihypertensive drugs used in the management.

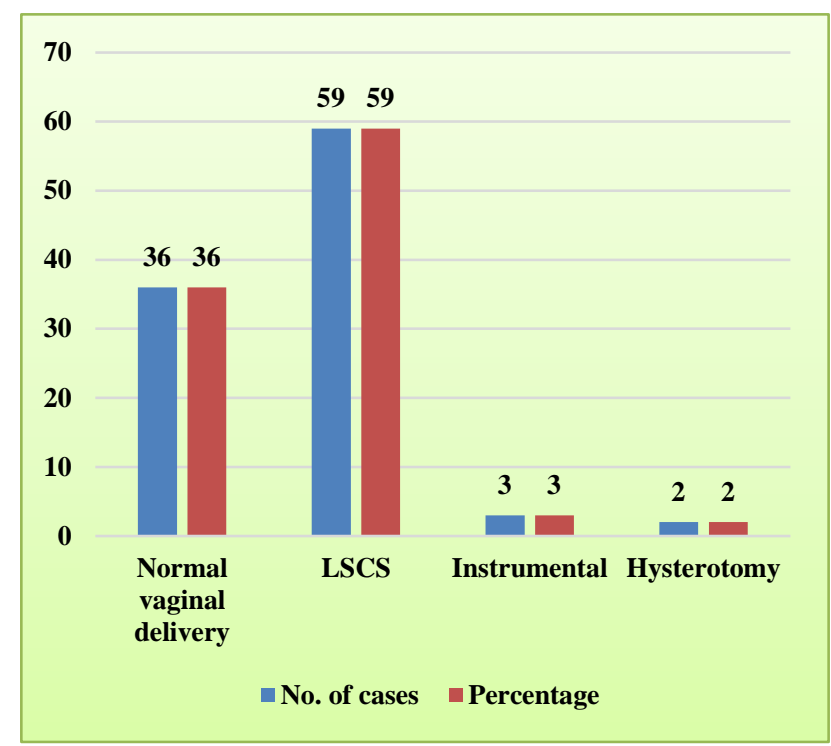

Figure 5: Distribution according to mode of delivery.

Most common indication for Caesarean Section was fetal distress (35.6\%) (Figure 6).

In this study, 37 patients had complications. 16(43.2\%) patients had eclampsia, $4(10.8 \%)$ patients had abruption, $8(21.6 \%)$ patients had HELLP syndrome, 6(16.2\%) patients had PPH, 1(2.7\%) patient each had DIC, pulmonary edema and renal dysfunction.

The most common maternal complication was eclampsia $(43.2 \%)$ and all were treated with Magnesium Sulphate (Figure 7).

Total number of maternal deaths were $5(5 \%), 2$ had sepsis with MODS and 3 had DIC as the cause of death (Figure 8). Out of 100 cases, 92 women had live births
$(92 \%)$ and 8 cases had Intrauterine Deaths (8\%). Out of 92 live births, 50 babies were admitted in NICU (54.3\%) (Figure 9). Out of 92 live births, 6(6.5\%) were $<1 \mathrm{~kg}$, $48(52.2 \%)$ were $1-2 \mathrm{~kg}, 38(41.3 \%)$ were $>2 \mathrm{~kg}$. Maximum number of patients $(52.2 \%)$ were $1-2 \mathrm{~kg}$ of weight (Figure 10). Out of 92 live births, $50(54.3 \%)$ had NICU admissions. $25(50 \%)$ were due to prematurity, $15(30 \%)$ were due to RDS and 10(20\%) were due to sepsis. Prematurity was the most common complication seen in $50 \%$ (Figure 11).

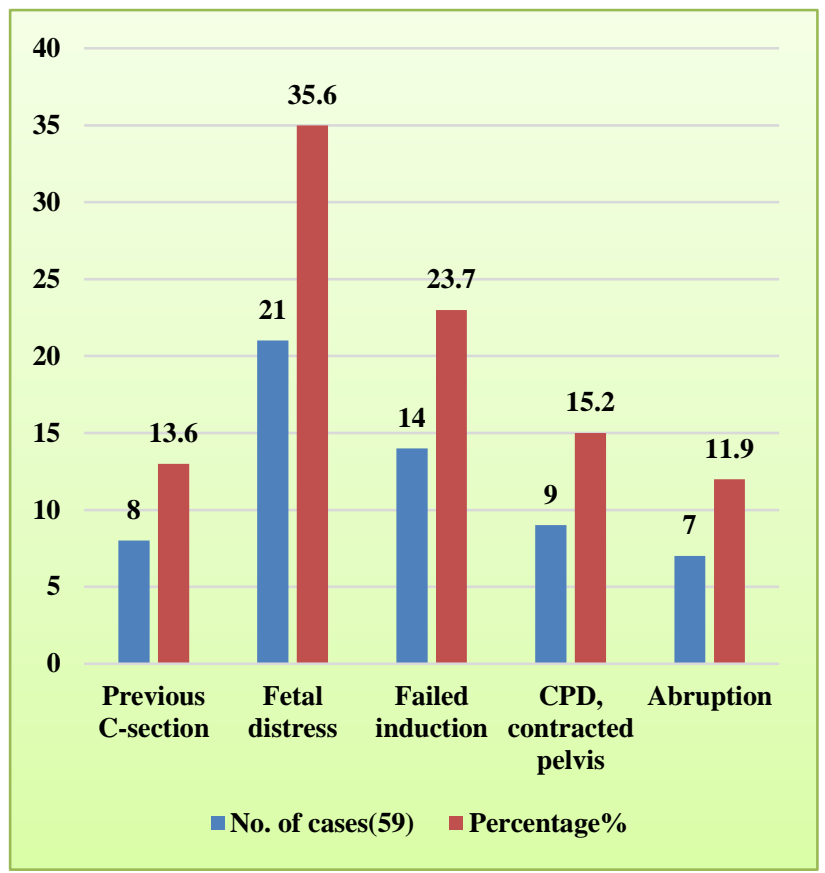

Figure 6: Indication of caesarean section.

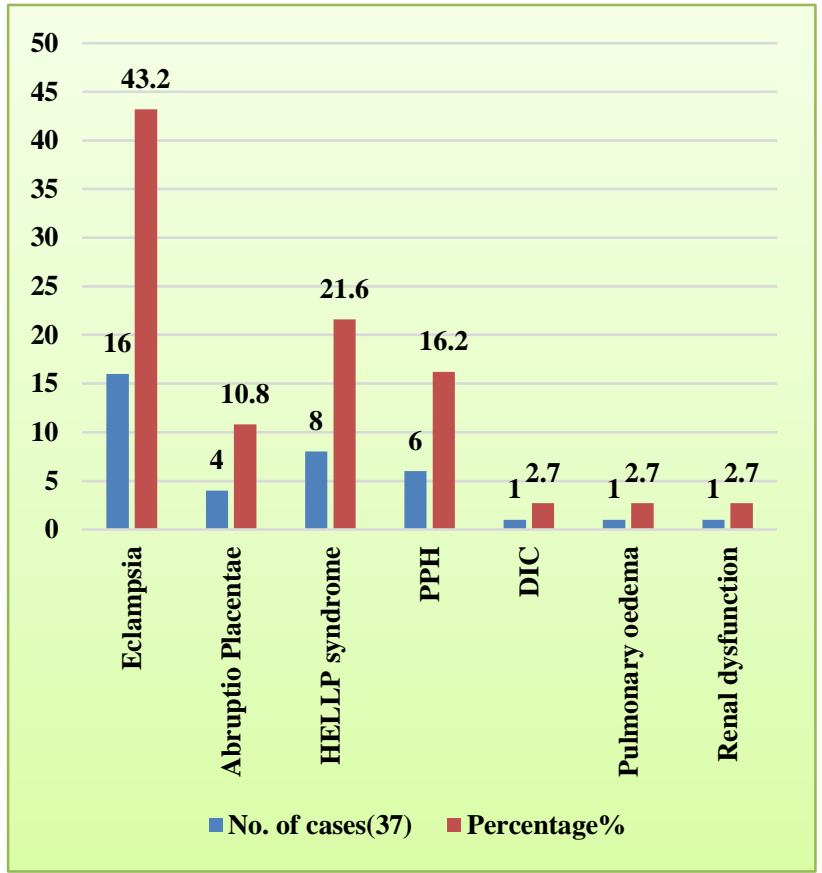

Figure 7: Distribution according to maternal complication. 


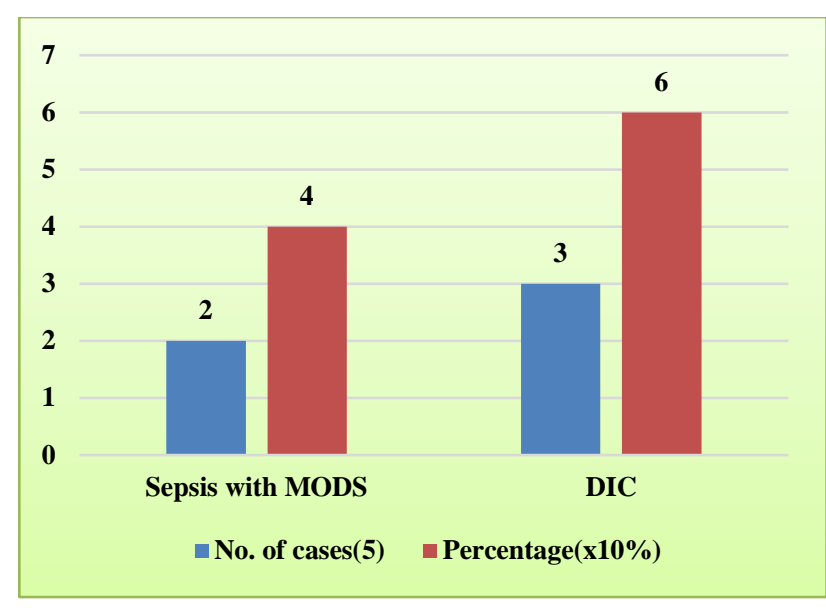

MODS: Multiple organ dysfunction syndrome, DIC:

Disseminated intravascular coagulation

Figure 8: Distribution according to cause of maternal death.

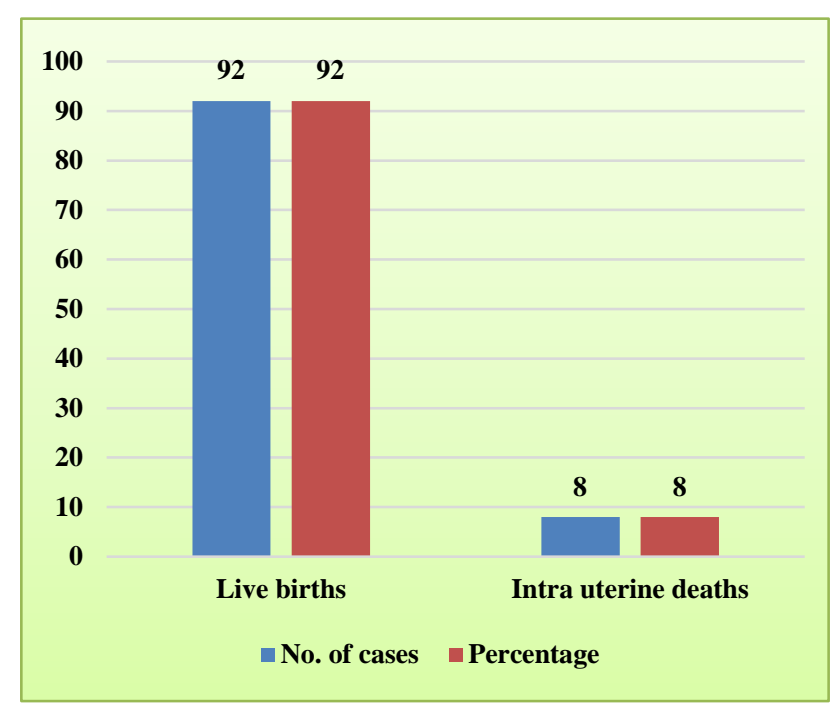

Figure 9: Distribution according to perinatal outcome.

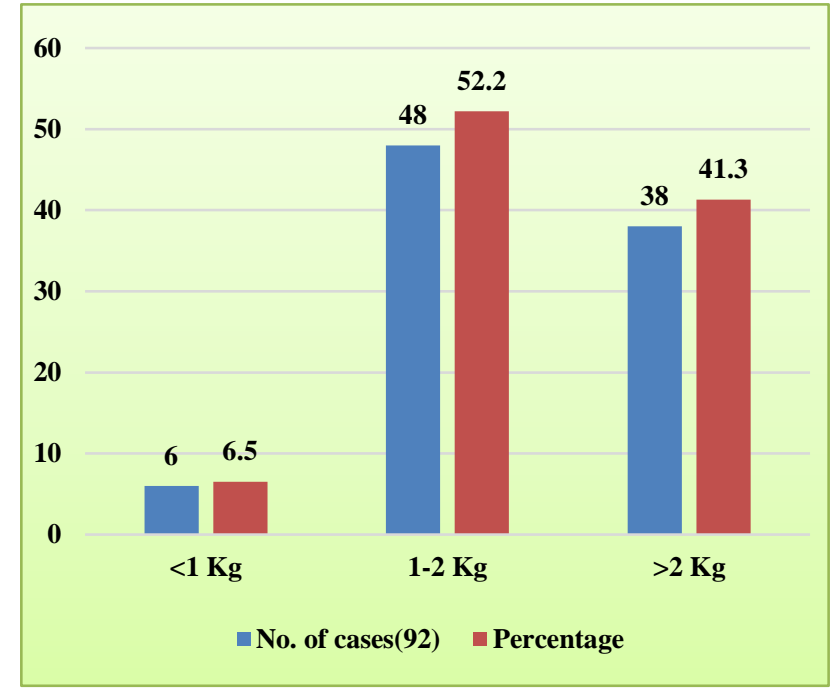

Figure 10: Distribution according to birth weight.

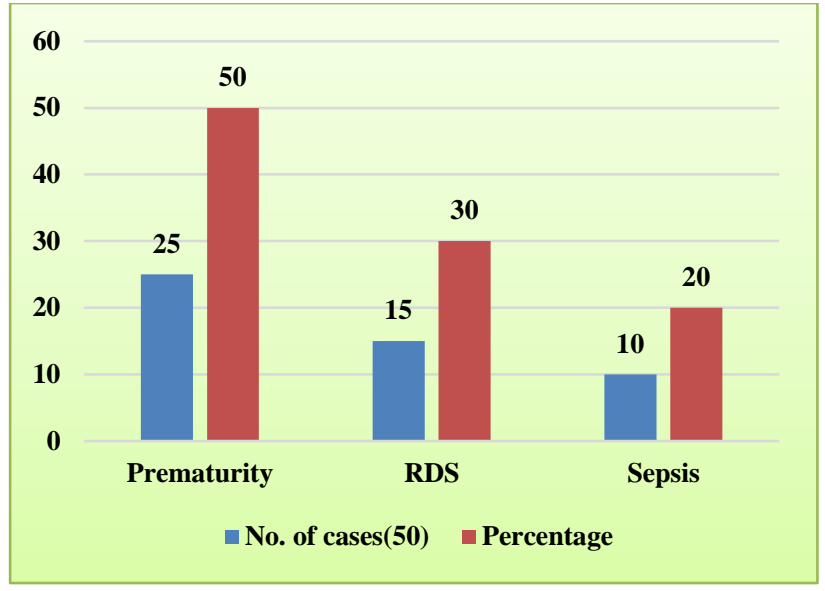

Figure 11: Causes of NICU admissions.

\section{DISCUSSION}

In the present study, out of 100 cases of severe preeclampsia and eclampsia, maximum number of patients i.e. $48 \%$ of the women were between age 21-25 years (Figure 1).

This is in accordance with the study by Onuh et al where mean age of women was $27.1 \pm 5.6$ years. ${ }^{4} 86 \%$ of women were unbooked cases having $<3$ antenatal visits and $82 \%$ had rural background in the present study. A study from rural Gujarat by Gandhi et al it was found that $72.6 \%$ of total cases of preeclampsia were unbooked patients. ${ }^{5}$ Mahalaxmi et al in their study in found $96.1 \%$ of patients to be unbooked. ${ }^{6}$

This shows that regular follow up of patients with frequent antenatal visits is essential as it helps in the early diagnosis and management of the preeclampsia and keeps it under control and prevents the development of complications. In the present study, 68\% women were primigravidae and only $32 \%$ women were multigravida which points to the association of nulliparity with severe pre-eclampsia (Figure 2).

Other studies notably by Sibai and Cunningham also support the view. Saxena et al in their study in found that $57.14 \%$ of PIH cases were primigravida and showed decreasing trend towards increasing parity.,

Abnormality in LFT was found in $18 \%$ of patients, abnormality in KFT was found in $19 \%$ of patients, platelet count $<1$ lakh was found in $25 \%$ of patients and peripheral smear revealed hemolysis in $8 \%$ of patients. (Table 1) Similar findings were seen by Pillai et al in where $19 \%$ had deranged LFT, $15 \%$ had deranged KFT and $7 \%$ had hemolysis on peripheral smear. ${ }^{9}$ Authors found that $92 \%$ of cases presented at gestational age of $>32$ weeks (Figure 3).

Singhal et al also reported similar findings. ${ }^{10}$ The most common mode of delivery was lower segment caesarean 
section in $59 \%$ of the cases (Figure 5) and the most common indication was fetal distress in $35.6 \%$ followed by failed induction in $23.7 \%$ of cases (Figure 6). The mode of delivery was determined by severity of maternal condition, Bishop's score, gestational age, fetal condition and laboratory findings.

Singhal et al in their study in 2009 reported $32 \%$ caesarean section rate and the most common indication was foetal distress seen in $59.28 \%$ of cases. ${ }^{10}$ Tufnell et al reported as high as $72 \%$ caesarean section rate. ${ }^{11}$

The high rate of caesarean section in the present study is due to emergency delivery approach taken to prevent further maternal and fetal complications due to severe pre-eclampsia and eclampsia especially in cases where the cervix is unfavorable for induction.

In this study, eclampsia was the most common maternal complication seen in $43.2 \%$ of cases, followed by HELLP Syndrome in $21.6 \%$ of cases and PPH in $16.2 \%$ of cases (Figure 7).

Various studies have reported abruptio placentae and HELLP Syndrome as more common complications. In a ten-year study done by Igberase et al the important causes of maternal mortality in severe pre-eclampsia were acute renal failure, disseminated intravascular coagulopathy (DIC), cardiac arrest, pulmonary oedema and cerebrovascular accidents. ${ }^{12}$

In present study, maternal deaths were $5(5 \%)$ and the most common cause of maternal death was Disseminated Intravascular Coagulation followed by sepsis with MODS (Figure 8). In this study there were 92 live births out of 100 (Figure 9) and out of these, there were 50 NICU admissions $(54.3 \%)$ and the most common causes of NICU admission was prematurity $(50 \%)$ followed by respiratory distress syndrome $(30 \%)$ (Figure 11$)$. In this study, $58.7 \%$ of newborns had birth weight $<2 \mathrm{Kg}$ (Figure 10). Tufnell et al reported $65.3 \%$ incidence of prematurity. ${ }^{11}$ The high incidence of preterm delivery could be attributed to the early intervention and induction of labour or LSCS done to avert further maternal and perinatal complications.

\section{CONCLUSION}

Pre-eclampsia and eclampsia continue to be significant causes of maternal and perinatal morbidity and mortality. Changes need to be made both at the grassroot and the tertiary level so that both low and high-risk pregnancy can be saved and to prevent conversion of low risk into high risk pregnancy. At the grassroot level the Traditional Birth Attendants need to be taught how to differentiate between low risk and high-risk pregnancy so that they refer the cases of preeclampsia to the higher centres as soon as they are diagnosed.
Even mild cases of preeclampsia need to be managed in tertiary or at least secondary centres for prevention of related dreadful obstetric emergencies and their prompt treatment if they occur. It is important to recognize early warning symptoms and signs so that life threatening complications can be averted. At the tertiary level the government should ensure that they are well equipped with facilities like blood bank with adequate amount of all the blood components and Intensive Care Unit for the mother and the neonate to prevent long term morbidity and mortality.

Also, the low risk pregnancies need not be seen in tertiary centres to prevent overloading of patients and to maintain quality of medical services. Antenatal care is found to be the most important intervention which can improve the outcome. Education and empowerment of women and accessible health care especially to socio-economically deprived and rural population is the need of the hour.

Funding: No funding sources

Conflict of interest: None declared

Ethical approval: The study was approved by the Institutional Ethics Committee

\section{REFERENCES}

1. Cunningham FG, Leveno KG, Bloom SL, Hauth JC, Rouse DJ, Catherine YS. Williams Obstetrics. 25th ed. New York, NY: McGraw Hill Companies;2018.

2. Khan KS, Wojdyla D, Say L, Gülmezoglu AM, Van Look PF. WHO analysis of causes of maternal death: a systematic review. The lancet. 2006;367(9516):1066-74.

3. Govt. of India (Sample Registration System) Maternal mortality in India, 1997-2003. Trends, causes and risk factors. Registrar General of India, New Delhi in collaboration with centre for Global Health Research, Toronto.

4. Onuh So, Aisien AO. Maternal and fetal outcome in eclamptic patients in Benin City, Nigeria. J Obstet Gynaecol. 2004;24(7):765-8.

5. Gandhi MR, Jani PS, Patel UM, Kakani CR, Thakar NC, Gupta N. Perinatal outcome in Pregnancy induced hypertension cases at GMERS Medical College, Dharpur-Patan, North Gujarat region, India :a prospective study. Int J Adv Med. 2015; 2(2): 1525.

6. Mahalakshmi G, Krishnaveni A, Nimma W, Vinusha $\mathrm{K}$. The study of maternal and perinatal outcome of eclampsia in a tertiary hospital. IOSR J Dental Med Sci. 2016;15(4):123-8.

7. Sibai BM, Cunningham FG; Prevention of preeclampsia and eclampsia. In Lindheimer MD, Roberts JM, Cunningham FG editors; Chesley's Hypertensive Disorders of Pregnancy. 3rd edition, Elsevier, New York, 2009: 215.

8. Saxena S, Srivastava PC, Thimmaraju KV, Mallick AK, Dalmia k, Das B. Socio-demographic profile of 
pregnancy induced hypertension in a tertiary care centre. Sch J Appl Med Sci. 2014; 67(2):3081-6.

9. Pillai SS. Fetomaternal outcome in severe preeclampsia and eclampsia: a retrospective study in a tertiary care centre. Int J Reprod Contracept Obstet Gynecol. 2017;6(9):3937-3941

10. Singhal S, Deepika, Anshu, Nanda S. Maternal and Perinatal outcome in severe pre-eclampsia and eclampsia. South Asian Federation Obstet Gynecol 2009;1(3):25-8.

11. Tufnell DJ, Jankowicz D, Lindow SW, Lyons G, Mason GC, Russell IF et al. Outcome of severe pre- eclampsia/eclampsia. Yorkshire 1999/2003. BrJ Obstet Gynecol. 2005;112(7):875-80.

12. Igberase GO, Ebeigbe PN. Eclampsia: ten-years of experience in a rural tertiary hospital in the Niger delta, Nigeria. J Obstet Gynaecol. 2006;26(5):414-7.

Cite this article as: Chaudhary N, Tyagi N, Tyagi S, Singhal S. Maternal and perinatal morbidity and mortality in severe pre-eclampsia and eclampsia in a tertiary care hospital: a prospective study. Int J Reprod Contracept Obstet Gynecol 2019;8:1414-20. 